\title{
What is popular? Distinguishing bullying and aggression as status correlates within specific peer normative contexts
}

\author{
Diego Palacios ${ }^{1}$ and Christian Berger ${ }^{2^{*}}$
}

\begin{abstract}
This study tested social status correlates of aggression and bullying and how these are influenced by peer groups' normative beliefs about aggression and prosocial behavior among 1165 fourth, fifth and sixth graders in Chile. Associations between aggression and popularity (positive) and social preference (negative) were confirmed, whereas bullying was negatively associated with both dimensions. Normative beliefs about aggression and prosocial behavior were assessed at the group level, while social status was assessed at the classroom level through peer nominations. Hierarchical Linear Analyses showed that in groups with a higher value associated with aggression, classmates rated aggressive peers as less popular but also less disliked. The status correlates of bullying remained unaffected by peer normative beliefs. The discussion focuses on the social function of aggression as compared to the social sanction associated with bullying, and on the specificity of these associations at different layers of the social ecology.
\end{abstract}

Keywords: Social status, Aggression, Bullying, Normative beliefs, Peer influence

\section{Background}

Several studies have shown that bullying and aggressive behaviors are influenced by the value that the peer context ascribes to them (Dijkstra \& Gest 2015; Faris \& Felmlee, 2011), thus affecting the likelihood of individuals to engage in these behaviors in order to conform to their group expectation (Berger \& Rodkin, 2012). Also, bullying and aggression are associated with social status (Cillessen \& Mayeux, 2004; Rodkin \& Berger, 2008). From this evidence it has been proposed that aggressive behaviors might be functional to achieve social status within the peer context (Berger \& Rodkin, 2012; Ellis \& Zarbatany, 2007). This evidence, along with the blurry boundaries between bullying and aggression (Cornell \& Bandyopadhyay, 2010) has led to assuming that both are affected equally by the peer context. Bullying, however, is characterized by the abusive use of power of an individual or group that intentionally and repeatedly attacks, excludes or humiliates others (Gini et al. 2011; Salmivalli, 2010). Aggression, by contrast, has been approached lately as a normative-yet not desirable-aspect of human nature and a basic process in interpersonal relationships (Hawley \& Vaughn, 2003). Fromm (1973) distinguished two forms of aggression: biologically adaptive aggression and malignant aggression. The former refers to a reactive behavior, oriented to self-preservation (triggered when feeling threatened), while the latter implies the intention to harm others. Based on this distinction, even though bullying and aggression may look behaviorally the same, bullying can be distinguished from aggression by its intentionality and abusive nature.

The present study tests the differences in the association between bullying, aggression and social status, assuming that the naturalization of aggression as a normal social behavior may make its association with status more dependent on the contextual value attributed to social behaviors, whereas the specific abusive and intentional nature of bullying may constitute a negatively sanctioned behavior per se within the peer ecology. Moreover, it explores the effects of peer normative beliefs about aggression and prosocial behavior on the distinct associations of bullying and aggression with social status.

\footnotetext{
*Correspondence: dfpalaci@uc.cl

${ }^{2}$ Pontificia Universidad Catolica de Chile, Santiago, Chile

Full list of author information is available at the end of the article
} 


\section{Adolescent social norms and beliefs: Setting the stage of what is popular}

Obtaining and maintaining a social position within the peer group and being accepted by peers are central developmental goals during adolescence (Ojanen et al. 2005). Adolescents are more likely to display aggression and bullying in peer contexts that ascribe higher social value to these behaviors (Berger \& Rodkin, 2012; Ellis \& Zarbatany, 2007; Sijtsema et al. 2009). Adolescents are influenced by peers when they engage in behaviors that (a) are associated with high status, (b) match the social norms of a valued or desired group, (c) are reinforced by peers, and (d) contribute to a favorable selfidentity (Brechwald \& Prinstein, 2011).

However, peer influence might not be exclusively related to behavioral patterns, but also to beliefs about aggression and bullying (Burton et al. 2013; Huesmann \& Guerra 1997; Salmivalli \& Voeten, 2004; Van Goethem et al. 2010). Huesmann and Guerra (1997) defined normative beliefs as the cognitions regarding the acceptability or unacceptability of certain behaviors, considering also emotional reactions. In other words, they constitute the validation and value ascribed to that behavior. Adolescents may be influenced to perform aggressive behaviors when their peer group ascribes social value (i.e., social status) to these behaviors (Huesmann \& Guerra, 1997; Jonkmann et al. 2009). By contrast, normative beliefs that enhance prosocial behavior may weaken the social value ascribed to aggressive and bullying behaviors, and therefore discourage their emergence. Recent studies have started to address both aggressive and prosocial behavior together from a peer relations perspective, showing similar patterns of social influence, and clear negative associations between them (Berger \& Rodkin, 2012; Dias et al. 2011; Molano et al. 2013). Thus, in order to better understand the social atmosphere in which these social behaviors occur, it is necessary to consider together behaviors and particular beliefs about them.

\section{Aggression, bullying, and social status}

Social contexts may attribute social functions to certain behaviors in order to achieve social goals, which during early adolescence refer to social prominence and acceptance (Ojanen et al., 2005). Previous research has consistently shown that aggression is associated with popularity (Cillessen \& Mayeux, 2004; Rose et al. 2004), visibility (Ellis \& Zarbatany, 2007), and being perceived as cool by peers (Rodkin et al. 2006). Cillessen and Mayeux (2004) found that relational aggression was predictive of popularity over time, whereas physical aggression, also associated with popularity, was less censored over time. In other words, if adolescents perceive that their peers value aggressive behavior, they may intentionally use it to gain social status, constituting a mechanism for social adaptation. Whereas, in the realm of bullying, several studies have shown that bullying may serve as a way of positioning individuals in the peer social hierarchy (Dijkstra et al. 2008; Olthof \& Goosens, 2007; Rodkin \& Berger, 2008). Bullies can be popular and socially central in their social groups (Rodkin et al., 2006).

\section{Distinguishing aggression and bullying as status correlates}

Cornell and Bandyopadhyay (2010) argued that bullying should be clearly distinguished from other forms of aggression. Consistently, Carrera et al. (2011) identified as a main shortcoming in previous research on bullying the lack of clarity in its definition, particularly in differentiating it from other forms of aggression.

Although aggression and bullying may overlap and share behavioral patterns, the peer processes that explain their emergence are not necessary the same. Bullying is built on abusive relationships, and thus its adaptive function-and consequently its sensitivity to peer influence-might not be straightforward. For instance, even though bullying might be used as a way to achieve peer acceptance, Olthof and Goosens (2007) showed that for boys this desire to be accepted was oriented specifically towards peers who also displayed bullying and antisocial behavior, but was unrelated or even negatively associated with their desire to be accepted by non-bullying peers. For girls, the same pattern was found regarding the desire to be accepted by boys. Another study found that the negative association between bullying and peer acceptance faded when bullies where high in machiavellianism (Wei \& Chen, 2012). Seemingly, Dijkstra et al. (2008) found that the associations between bullying and peer rejection (positive) and peer acceptance (negative) were weakened when the perpetrator of bullying behavior was highly popular. These differences may be due to attributional biases and also to peer beliefs regarding these behaviors (Lansu et al. 2013; van Goethem et al., 2010). These studies suggest that, although both aggression and bullying are associated with popularity, they seem to imply different interpersonal configurations that become clearer when considering the associations of aggression and bullying with social preference as a distinct dimension of social status that refers to likeability (Cillessen \& Mayeux, 2004; Rose et al., 2004).

\section{The present study}

Even though aggression and bullying may be displayed through similar behavioral patterns (i.e., physical or relational actions), they constitute different interpersonal configurations. The present study focuses on differentiating these behaviors by means of their associations with social status, distinguishing popularity (as a measure of prominence) and social preference (as a measure of likeability). Moreover, this study considers that group 
normative beliefs determine specific social contexts that ascribe social value to behaviors. From this perspective, aggression might be considered a functional and even validated way to achieve social status. However, peers might sanction bullying due to its abusive and immoral character. Therefore, this study tests whether the behavioral (i.e., aggression and bullying) correlates of social status are equally affected by group normative beliefs. Accordingly, the following hypotheses were formulated: (1) Bullying and aggression are positively associated with popularity and negatively to social preference; and (2) Peer group's normative beliefs about aggression (positively) and prosocial behavior (negatively) predict individual bullying and aggression among group members. Also, considering the differences between aggression and bullying (3) it is expected that the association between aggression and popularity would be more sensitive to peer normative beliefs due to its normative character, while the association between bullying and social status, due to its abusive nature, will not depend on the social context.

Although studies show that bullying and physical aggression are more prevalent among boys, the associations between aggression and bullying with social status seem to hold for both genders; however, evidence is inconclusive (Card et al. 2005). Seemingly, despite the strong gender segregation in adolescent groups (Adler \& Adler, 1998), studies on group influences have found similar patterns for boys and girls groups (Berger \& Rodkin, 2012; Chung-Hall \& Chen, 2010; Ellis \& Zarbatany, 2007). Therefore, and since the focus of these analyses was on the differences between bullying and aggression, we controlled for potential gender differences without formulating specific hypotheses regarding gender.

\section{Method \\ Participants}

Participants were 1165 fourth, fifth and sixth graders (51.2 \% males) from 30 classrooms in four schools in metropolitan Santiago, Chile (according to the national socioeconomic classification, two schools corresponded to middle, one upper-middle and one lower-middle SES). Overall parental consent rate was $89.5 \%$; however, several classrooms had lower rates of participation (due to low parental consent rates and absence of participants). Since the analytical unit was the classroom, only classrooms that had a participation rate higher than $80 \%$ were included in the analyses, leaving a final sample of 19 classrooms (711 participants). Attrition analyses showed that participants who were excluded (i.e. members of classrooms with more than $20 \%$ absences) did not differ in bullying or physical aggression $(t \mathrm{~s}=1.21$ and 0.22 ). Data were collected in the fall of 2012 .

\section{Variables and measures}

Standard peer nominations procedures were used to assess social status (Berger \& Rodkin, 2012; Cillessen \& Mayeux, 2004; Logis, Rodkin, Gest, \& Ahn, 2013). Participants were asked to check on a roster all the names of their classmates who best fit several descriptors. For each participant on each descriptor, a proportion of nominations received over the maximum potential nominations was calculated. Scores were then $\mathrm{z}$-standardized at the sample level.

\section{Social preference}

Participants were asked to nominate their classmates with whom they would like to spend time with the most and the least. Least liked nominations were subtracted from most liked nominations scores.

\section{Popularity}

Participants nominated classmates that they considered the most popular and unpopular in their classroom: unpopular scores were subtracted from popular scores.

\section{Bullying and aggression}

The Illinois Bullying and Fighting Scale (Espelage \& Holt, 2001) was used to assess bullying. This scale is a selfreported instrument featuring 18 items with a scoring of four points (never, almost never, sometimes, almost every time) in a likert type scale. The scale features three subscales: Bullying, Fighting, and Victimization. Through confirmatory factor analysis we checked the three factors structure of the scale $(C F I=0.950$, RMSEA $=0.045)$. For the present study we adopted the same criteria as Espelage and Holt (2001), considering items that loaded higher than 0.50 and with cross loadings lower than 0.30 , leaving three items for Bullying and five for Fighting, respectively. The bullying subscale included three items referring to intentional behaviors, aimed at establishing a power imbalance between peers and harming others, therefore, even though a definition of bullying was not given to the participants, we agree with Espelage and Holt (2001) that all items constitute an appropriate expression of bullying. Items used in the present study were: "I excluded others", "I spread rumors about others", and "I helped harass other students". The fighting subscale was used as a measure of direct aggression and included these items: "I got into a physical fight", "I got into a physical fight when angry", "I threatened to hit or hurt another student", "I hit back when someone hit me first", and "I fought students I could easily beat". The scale has been used with Spanish speaking samples, and for the present study was adapted to the Chilean population. Cronbach's alpha for both subscales were 0.79 and 0.83 , respectively. 


\section{Normative beliefs about aggression}

The Normative Beliefs About Aggression Scale (NBAGGS; Huesmann \& Guerra, 1997) includes 20 items with a scoring of four points in a likert type scale. Sample items are "if you are angry, it is OK to say mean things to other people", and "it is wrong to insult other people". The scale was translated into Spanish by the research team. Cronbach's alpha for the present sample was 0.83 .

\section{Normative beliefs about prosociality}

A parallel scale to the NBAGGS was developed for this purpose. The Normative Beliefs About Prosociality (CNPROS; Berger et al. 2015) follows the same structure, and sample items are "in general one should only help others when they ask for help", and "it is not ok to repeat rumors about classmates". Cronbach's alpha for the present sample was 0.70 .

Group norms for normative beliefs about aggression and prosociality were calculated as the average of group members' scores on these scales, as suggested by previous studies (Berger \& Rodkin, 2012; Ellis \& Zarbatany, 2007; Espelage et al., 2003).

\section{Peer groups}

Peer groups were identified through the Social Cognitive Mapping (SCM) procedure (Cairns et al. 1985). Participants could nominate classmates with whom they hang around a lot (i.e., their peer group). They could also report on two other groups of classmates that hang out together. SCM identifies the social network of the classroom by aggregating reports of all members regarding their own group and other peer groups present in the classroom; hence, the social network was based on the consensus of all classmates' perceptions. Since Hierarchical Linear Modeling (HLM) requires each individual to be nested in only one level 2 unit (in this case, groups), a strict criterion for group membership was used. In order to ensure affiliation to a certain group, two students needed to be nominated as members of the same group at least four times (i.e., both students nominated themselves as members of the same group, and two other students also nominated them together as members of the same group). This criterion was established considering the large classroom size (average of 37 members), and to clearly locate each participant in only one group. Preliminary analyses with this criterion showed descriptive features similar to those observed in a different sample of Chilean adolescents such as group stability and number of isolated individuals (Berger \& Rodkin, 2012). Only groups with three or more members were included in the analyses.

A total of 79 groups were identified, with an average of 9 members (median $=7$; group range $=3-22$ students). Twenty-eight (28) participants were unable to be clearly located in a specific group, and 7 were considered isolated, and these 35 students were excluded from further analyses. Descriptive analyses showed that members who were excluded were perceived as less popular and less socially preferred ( $t \mathrm{~s}=-5.09$ and $-5.36, p \mathrm{~s}<0.01)$ as compared to participants who were part of identified groups; no differences were observed regarding bullying and aggression.

\section{Procedure}

Surveys were administered to the whole classroom in regular classroom hours. Each participant answered the survey by him or herself, and research assistants answered questions as needed. All instruments and procedures were approved of by the Institutional Review Board of the local university and by the funding institution. Parental active consent and adolescents' assent were gathered for all participants.

\section{Analytical strategy}

Since the research question that guided this study referred to the interplay between individual and group factors in predicting social status, Hierarchical Linear Modeling (HLM; Raudenbush \& Bryk, 2002) was considered appropriate. HLM assesses the effects of level 2 variables (group level variables) both on the intercept and on the slopes of level 1 (individual) predictors. Separate models were tested for popularity and social preference. All variables were grand mean centered, since the main research questions referred to the interaction between level 1 and level 2 variables (Enders \& Tofighi, 2007).

\section{Results}

Descriptive analyses are presented in Table 1. Popularity and social preference were significantly associated $(r=0.47$, $p<0.01)$. The correlation between aggression and popularity was significantly positive, but weak $(r=0.09, p<$ $0.05)$, and significant and negative with social preference $(r=-0.22, p<0.01)$; bullying only correlated negatively with social preference $(r=-0.20, p<0.01)$. Aggression and bullying were positively associated $(r=0.44, p<0.01)$. This correlational pattern was similar for boys and girls, with the exception of the association between bullying and

Table 1 Mean, standard deviation, range, and correlations between individual variables

\begin{tabular}{lllllllll}
\hline & $X$ & SD & Min. & Max. & 1 & 2 & 3 & 4 \\
\hline 1. Popularity & -0.04 & 1.01 & -1.85 & 2.69 & - & & \\
2. Social Pref. & -0.01 & 0.90 & -2.98 & 2.17 & $0.47^{* *}$ & - & & \\
3. Bullying & 1.48 & 0.58 & 1 & 3.67 & -0.06 & $-0.20^{* *}$ & - \\
4. Aggression & 1.57 & 0.63 & 1 & 4.43 & $0.09^{*}$ & $-0.22^{* *}$ & $0.44^{* *}$ & - \\
\hline
\end{tabular}

Note: ${ }^{*} p<.05 ;{ }^{* *} p<0.01$ (two-tailed) 
social preference that was significant for boys $(r=-0.29$, $p<0.01)$ but not for girls $(r=-0.09, \mathrm{~ns})$.

Group normative beliefs about aggression and prosociality were calculated as an aggregate of all group members' scores. Both variables were negatively associated at the group level $(r=-0.38, p<0.01)$. Group size was uncorrelated to both variables.

\section{Hierarchical linear modeling}

Separate hierarchical linear analyses for perceived popularity and social preference were performed. Standard procedures suggested by Raudenbush and Bryk (2002) were followed. First, a fully unconditional model was tested. Intraclass correlations showed that $54 \%$ of the variance of popularity and $64 \%$ of the variance of social preference was explained by differences between groups. A second model including only level 1 predictors (bullying and aggression) was then tested, controlling for gender. Next, a third model including also level 2 predictors (normative beliefs about aggression and prosociality, respectively) regressed only on the intercept was tested. The final model considered also level 2 variables predicting both the intercept and the slopes of level 1 predictors.

Tables 2 and 3 present the results for popularity and social preference, respectively. As can be observed in models 2 , bullying was negatively associated with popularity and social preference (est. $=-0.181$ and $-0.133, p \mathrm{~s}<0.01$ ), whereas aggression was positively associated with popularity (est. $=0.146, p<0.05$ ) but negatively with social preference (est. $=-0.240, p<0.01$ ). Boys and girls did not differ regarding popularity or social preference.

Individual popularity was not associated with group normative beliefs about aggression and prosociality (model 3 in Table 2), whereas normative beliefs about prosocial behavior were associated with social preference (model 3 in Table 3; 0.379, $p<0.05$ ).

Finally, for groups which more highly valued aggressive behavior, the effect of individual aggression on popularity and social preference was reduced (model 4 in Tables 2 and 3, and Fig. 1). Seemingly, in these groups the negative association between aggression and social preference decreases. These results suggest that when groups ascribe a higher value to aggression, peer dislike associated with aggressive behaviors decreases, but aggressive adolescents also become less salient (i.e. popular) within these groups. The associations between bullying and both social status measures were not affected by group normative beliefs.

\section{Discussion}

During the last decade several studies have identified positive associations between aggressive behavior and

Table 2 HLM models regarding the effects of individual bullying, aggression, gender, and group normative beliefs about aggression and prosociality on individual popularity

\begin{tabular}{|c|c|c|c|c|c|c|c|c|}
\hline & \multicolumn{2}{|l|}{ Model 1} & \multicolumn{2}{|l|}{ Model 2} & \multicolumn{2}{|l|}{ Model 3} & \multicolumn{2}{|l|}{ Model 4} \\
\hline & Est. & SE & Est. & SE & Est. & SE & Est. & SE \\
\hline \multicolumn{9}{|l|}{ Intercept } \\
\hline Base & $-.181^{* *}$ & .085 & $-.179^{* *}$ & .088 & $-.179 * *$ & .088 & $-.171^{* *}$ & .090 \\
\hline Gr. NB prosociality & & & & & -.086 & .216 & -.073 & .208 \\
\hline Gr. NB aggression & & & & & -.129 & .204 & -.156 & .200 \\
\hline \multicolumn{9}{|l|}{ Bullying } \\
\hline Base & & & $-.181^{* * *}$ & .069 & $-.180^{* * *}$ & .069 & $-.183^{* * *}$ & .070 \\
\hline \multicolumn{9}{|l|}{ Aggression } \\
\hline Base & & & $.146^{* * *}$ & .055 & $.147^{* * *}$ & .054 & $.176^{* * *}$ & .057 \\
\hline Gr. NB prosociality & & & & & & & -.211 & .141 \\
\hline Gr. NB aggression & & & & & & & $-.310^{*}$ & .161 \\
\hline \multicolumn{9}{|l|}{ Gender } \\
\hline Base & & & .076 & .121 & .072 & .122 & .085 & .120 \\
\hline$\sigma^{2}$ & .584 & & .555 & & .555 & & .554 & \\
\hline $\mathrm{T}$ & .495 & & .509 & & .523 & & .519 & \\
\hline Reduced variance within group & & & .050 & & .050 & & .051 & \\
\hline Reduced variance between group & & & & & -.057 & & -.048 & \\
\hline Deviance & 1794.15 & & 1527.69 & & 1530.24 & & 1530.94 & \\
\hline Intraclass correlation & .54 & & & & & & & \\
\hline
\end{tabular}

Note. ${ }^{*} p<0.1 ;{ }^{* *} p<0.05 ;{ }^{* * *} p<0.01$

Gr. NB group Normative Beliefs about prosociality and aggression, respectively 
Table 3 HLM models regarding the effects of individual bullying, aggression, gender, and group normative beliefs about aggression and prosociality on individual social preference

\begin{tabular}{|c|c|c|c|c|c|c|c|c|}
\hline & \multicolumn{2}{|l|}{ Model 1} & \multicolumn{2}{|l|}{ Model 2} & \multicolumn{2}{|l|}{ Model 3} & \multicolumn{2}{|l|}{ Model 4} \\
\hline & Est. & SE & Est. & SE & Est. & SE & Est. & SE \\
\hline \multicolumn{9}{|l|}{ Intercept } \\
\hline Base & -.083 & .069 & -.076 & .069 & -.073 & .065 & -.063 & .067 \\
\hline Gr. NB prosociality & & & & & $.379^{* *}$ & .152 & $.387^{* *}$ & .153 \\
\hline Gr. NB aggression & & & & & -.154 & .147 & -.184 & .150 \\
\hline \multicolumn{9}{|l|}{ Bullying } \\
\hline Base & & & $-.133^{* *}$ & .053 & $-.124^{* *}$ & .057 & $-.125^{* *}$ & .057 \\
\hline \multicolumn{9}{|l|}{ Aggression } \\
\hline Base & & & $-.240^{* * *}$ & .060 & $-.217^{* * *}$ & .058 & $-.185^{* * *}$ & .064 \\
\hline Gr. NB prosociality & & & & & & & -.157 & .125 \\
\hline Gr. NB aggression & & & & & & & $-.286^{*}$ & .151 \\
\hline \multicolumn{9}{|l|}{ Gender } \\
\hline Base & & & -.095 & .103 & -.105 & .106 & -.093 & .106 \\
\hline$\sigma^{2}$ & .546 & & .494 & & .492 & & .490 & \\
\hline T & .305 & & .285 & & .248 & & .490 & \\
\hline Reduced variance within group & & & .095 & & .099 & & .103 & \\
\hline Reduced variance between group & & & & & .187 & & -.607 & \\
\hline Deviance & 1720.23 & & 1428.84 & & 1420.75 & & 1422.14 & \\
\hline Intraclass correlation & .64 & & & & & & & \\
\hline
\end{tabular}

Note. ${ }^{*} p<0.1 ;{ }^{* *} p<0.05 ;{ }^{* * *} p<0.01$

Gr. NB group Normative Beliefs about prosociality and aggression, respectively

social status (Cillessen \& Mayeux, 2007). The present study builds on this knowledge by questioning what is really popular within specific peer contexts. These results provide a significant step in this direction, by distinguishing aggression and bullying as two behaviors that may look behaviorally similar, but that seem to be different regarding their social implications.

Bullying and aggression have been usually considered together in previous studies, and to some degree these two constructs have been assimilated in the literature and particularly by the general population. It seems obvious to consider that children and adolescents who display higher levels of aggression are more likely to be bullies, and also that their peers will perceive individuals who engage in bullying as aggressive. However, this might lead to wrong assumptions, such as considering peer aggression and bullying as similar social behaviors, or as equally affected by the social context. Bullying implies abuse and intention to harm, and thus it has been defined as immoral (Gini et al., 2011); by contrast aggressive behavior may be considered a behavior that due to its social function can become natural among early adolescents, but does not imply the intention to harm.

The present study also shows that aggression and bullying go beyond individual differences and attributes, being influenced by the social contexts in which they take place. More than assuming a straightforward group effect on individual behavior, these behaviors may become functional depending on the value and acceptance that groups ascribe to them. Several studies have shown that individual behavior is explained in part by group norms regarding these behaviors (Duffy \& Nesdale, 2009; Potocnjak et al. 2011). The present study expands these findings by showing that group influence on these behaviors may be a reinforcing factor via its association with social status, but also by the value that groups ascribe to aggression and bullying by means of their beliefs.

This study shows that normative beliefs about aggression constitute significant contextual factors that are associated with what is popular and socially preferred. Results suggest that the correlation between popularity and aggressive behavior (which barely reached significance at level 1 for the overall sample), increases in groups were aggression is less valued and normative (closely reaching significance levels). By contrast, aggressive adolescents who are members of groups with a higher value associated with aggression become more disliked. In this sense, the uniqueness associated with being aggressive may foster the visibility and consequent popularity of these adolescents. However, this uniqueness also has its costs, since groups that are more positive 

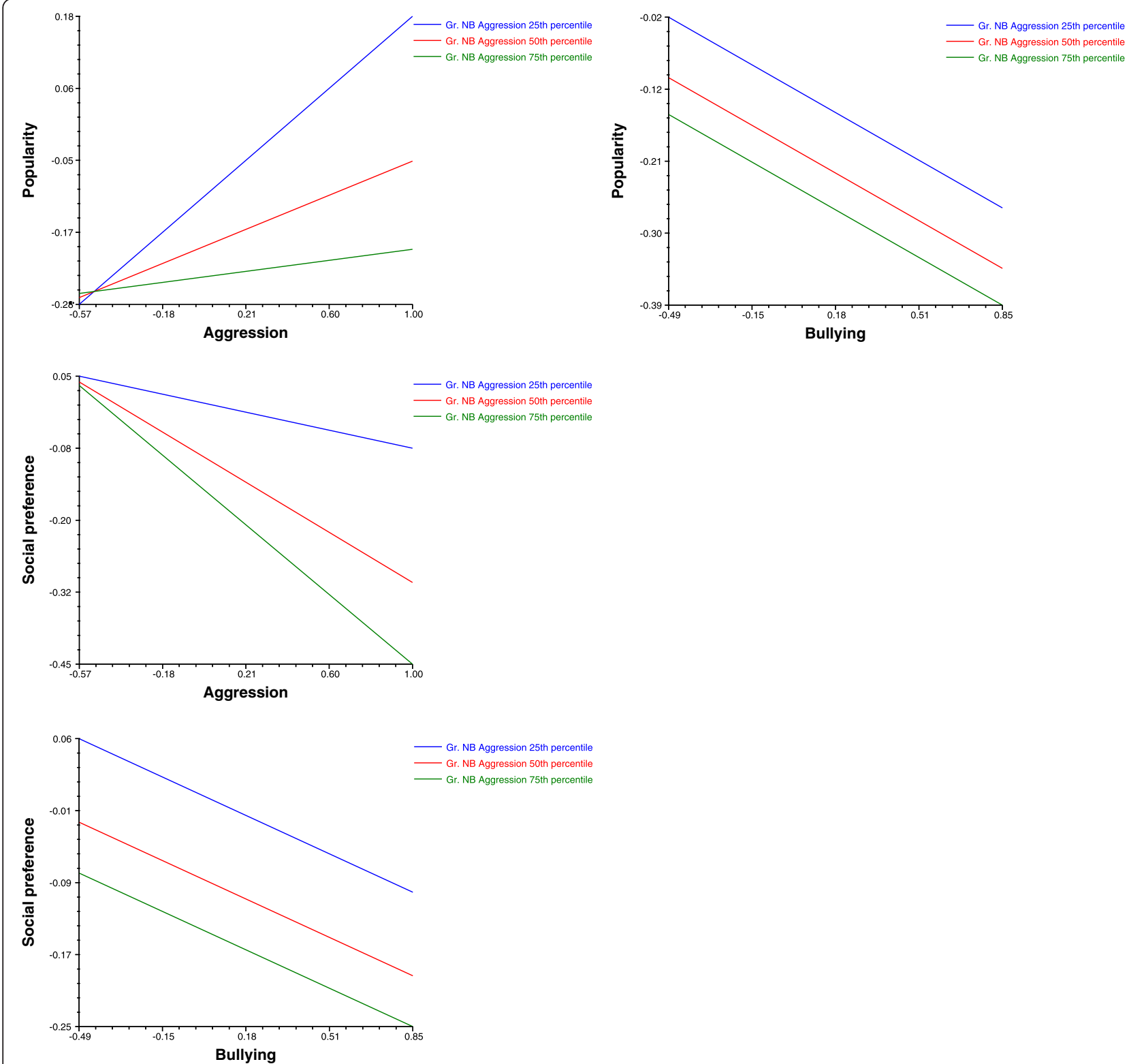

Fig. 1 Slopes of aggression (left) and bullying (right) regressed on popularity (upper panel) and social preference (lower panel), by different levels of group normative beliefs about aggression

towards aggression are also highly disliked by their classmates. This twofold effect is in line with recent studies showing that aggression implies a 'bright and a dark side', depending on how it is conceptualized (Cillessen \& Mayeux, 2007), and also calls for future research to identify profiles of aggressive adolescents (Shi \& Xie, 2012).

These findings should be taken carefully, since normative beliefs were assessed at the group level (i.e., clique), and social status and aggression were assessed as a classroom consensus through peer nominations. From a conceptual standpoint it should be noted that the close peer group is considered the niche for peer influence, since homophily on bullying and aggression have been described as part of more intimate, close relationships (Berger \& Rodkin, 2012; Ellis \& Zarbatany, 2007). However, social status refers to an individual's prestige, visibility, and affection in a wider social environment (Cotterell, 1996), like the whole classroom. Since aggression is overall rejected by peers (as shown by the results at the individual level), and aggressive adolescents tend to be part of groups that display more aggression (i.e., homophily), they will be more disliked by their classmates. Therefore, even though it may be counterintuitive to find that the association between 
aggression and popularity decreases in groups with higher value ascribed to aggression, this may be explained by the fact that these adolescents, due to their high aggressive orientation towards peers will be perceived as less popular and rejected at higher levels by the classroom. Another potential explanation for this finding is that groups with higher normative beliefs about aggression may include the most aggressive peers in the classroom, thus having little variation between them and reducing the possibility of finding correlations with other variables. In any case, future studies should test these hypotheses by differentiating popularity and social preference both at the classroom and at the group level, and also by assessing normative beliefs at both levels.

The negative associations of bullying with popularity and social preference, by contrast, were not affected by the normative peer context. Bullying seemed to be less influenced by peer effects, and negatively sanctioned independent of the value the group ascribed to aggression. Therefore, bullying seems to be unpopular and socially disliked by peers per se as an individual behavior, probably due to its abusive and immoral character.

The present study has some limitations that should be acknowledged. Previous studies in these areas have pointed out the importance of distinguishing between different types of aggression (Prinstein \& Cillessen, 2003) and bullying (Leff, 2007). In the present study, bullying was measured with self-reports, and no definition of bullying was given to participants. However, the factorial structure of the scale was checked, and it was decided to use a stricter items' selection to keep only the items that tackled bullying behavior. Future studies could test the associations of subtypes of aggression with social status and the effects of group features, and consider different reporting sources (peer, self, teachers), since previous studies have shown differences regarding who reports on bullying (Berger \& Rodkin, 2009; Zimmer-Gembeck et al., 2013). Another limitation is the cross-sectional nature of the data that does not allow for testing causal associations and developmental trends. Longitudinal analyses should complement these results to gain a better understanding of peer processes, for instance, disentangling influence and selection processes (Veenstra \& Dijkstra, 2011). Finally, it is worth noting that the effects of group normative beliefs about the association between aggression and social status only reached significance levels; therefore, results should be taken with caution. Despite these limitations, the sample size and the understudied context in which it was carried out constitute strengths of this study, contributing to the previous knowledge on peer influence processes on aggression and bullying. These results suggests that aggression may be perceived as a given fact of interpersonal relationships, whereas bullying, due its abusive nature, might be less accepted.
Competing interests

The authors declare that they have no competing interests.

\section{Author details}

${ }^{1}$ Centro de Medicion MIDE UC, Pontificia Universidad Catolica de Chile, Santiago, Chile. ${ }^{2}$ Pontificia Universidad Catolica de Chile, Santiago, Chile.

Received: 9 March 2016 Accepted: 7 April 2016

Published online: 14 April 2016

\section{References}

Adler PA, Adler P. Peer power. Preadolescent culture and identity. New Brunswick: Rutgers University Press; 1998.

Berger C, Rodkin PC. Male and female victims of male bullies: Social status differences by gender and informant source. Sex Roles. 2009;61:72-84. doi:10.1007/s11199-009-9605-9.

Berger C, Rodkin PC. Group influences on individual aggression and prosociality: Early adolescents who change peer affiliations. Soc Dev. 2012;21:396-413. doi:10.1111/j.1467-9507.2011.00628.x.

Berger C, Rojas N, Rasse C, Cuadros O. Diseño y validación de la Escala de Creencias Normativas ante la Prosocialidad en adolescentes chilenos. Psykhe. 2015. In press.

Brechwald W, Prinstein M. Beyond homophily: A decade of advances in understanding peer influence processes. J Res Adolesc. 2011;21:166-79. doi:10.1111/j.1532-7795.2010.00721.x.

Burton KA, Florell D, Wygant DB. The role of peer attachment and normative beliefs about aggression on traditional bullying and cyberbullying. Psychol Sch. 2013:50:103-15. doi:10.1002/pits.21663.

Cairns R, Perrin J, Cairns B. Social structure and social cognition in early adolescence: Affiliative patterns. J Early Adolesc. 1985;5:339-55.

Card N, Hodges E, Little T, Hawley P. Gender effects in peer nominations for aggression and social status. Int J Behav Dev. 2005;29:146-55. doi:10.1080/ 01650250444000414.

Carrera M, DePalma R, Lameiras M. Toward a more comprehensive understanding of bullying in school settings. Educ Psychol Rev. 2011;23:479-99. doi:10.1007/ s10648-011-9171-X.

Chung-Hall J, Chen X. Aggressive and prosocial peer group functioning: Effects on children's social, school, and psychological adjustment. Soc Dev. 2010;19:659-80. doi:10.1111/j.1467-9507.2009.00556.x.

Cillessen AHN, Mayeux L. From censure to reinforcement: Developmental changes in the association between aggression and social status. Child Dev. 2004;75:147-63. doi:10.1111/j.1467-8624.2004.00660.x.

Cillessen AHN, Mayeux L. Variations in the association between aggression and social status: Theoretical and empirical perspectives. In: Hawley P, Little T, Rodkin P, editors. Aggression and adaptation: The bright side to bad behavior. Mahwah: Lawrence Erlbaum Associates; 2007. p. 135-56.

Cornell D, Bandyopadhyay S. The assessment of bullying. In: Jimerson S, Swearer S, Espelage D, editors. Handbook of bullying in schools: An international perspective. New York: Routledge; 2010. p. 265-76.

Cotterell J. Social networks and social influences in adolescence. London: Routledge; 1996.

Dias T, Lisboa C, Koller S, DeSousa D. Aggression and pro-sociability: Risk and protective dynamics in popularity and bullying processes. Psykhe. 2011;20:53-63. doi:10.4067/S0718-22282011000200005.

Dijkstra JK, Gest S. Peer norm salience for academic achievement, prosocial behavior, and bullying: Implications for adolescent school experiences. J Early Adolesc. 2015;35:79-96. doi:10.1177/0272431614524303.

Dijkstra JK, Lindenberg S, Veenstra R. Beyond the class norm: Bullying behavior of popular adolescents and its relation to peer acceptance and rejection. J Abnorm Child Psychol. 2008;36:1289-99. doi:10.1007/s10802-088-9251-7.

Duffy A, Nesdale D. Peer groups, social identity, and children's bullying behavior. Soc Dev. 2009;18(1):121-39. doi:10.1111/j.1467-9507.2008.00484.x.

Ellis W, Zarbatany L. Peer group status as a moderator of group influence on children's deviant, aggressive, and prosocial behavior. Child Dev. 2007;78:1240-54. doi:10.1111/j.1467-8624.2007.01063.x.

Enders CK, Tofighi D. Centering predictor variables in cross-sectional multilevel models: A new look at an old issue. Psychol Methods. 2007;12(2):121-38. doi:10.1037/1082-989X.12.2.121.

Espelage D, Holt M. Bullying and victimization during early adolescence: Peer influences and psychosocial correlates. J Emot Abus. 2001;2:123-42. doi:10.1300/J135v02n02_08. 
Espelage DL, Holt MK, Henkel RR. Examination of peer-group contextual effects on aggression during early adolescence. Child Dev. 2003;74:205-220. doi: 10. 1111/1467-8624.00531.

Faris R, Felmlee D. Status struggles: Network centrality and gender segregation in same- and cross-gender aggression. Am Sociol Rev. 2011;76:48-73. doi:10.1177/0003122410396196.

Fromm E. The anatomy of human destructiveness. New York: Henry Holt; 1973.

Gini G, Pozzoli T, Hauser M. Bullies have enhanced moral competence to judge relative to victims, but lack moral compassion. Personal Individ Differ. 2011;50(5):603-8. doi:10.1016/j.paid.2010.12.002.

Hawley P, Vaughn B. Aggression and adaptive functioning: The bright side to bad behavior. Merrill-Palmer Q. 2003;49:239-42. doi:10.1353/mpq.2003.0012.

Huesmann R, Guerra N. Children's normative beliefs about aggression and aggressive behavior. J Pers Soc Psychol. 1997;72:408-19.

Jonkmann K, Trautwein U, Lüdtke O. Social dominance in adolescence: The moderating role of the classroom context and behavioral heterogeneity. Child Dev. 2009;80:338-55. doi:10.1111/j.1467-8624.2009.01264.x.

Lansu T, Cillessen AHN, Bukowski W. Implicit and explicit peer evaluation: Associations with early adolescents' prosociality, aggression, and bullying. J Res Adolesc. 2013. doi: 10.1111/jora.12028.

Leff S. Bullying and peer victimization at schools: Considerations and future directions. Sch Psychol Rev. 2007;36:406-12.

Logis H, Rodkin PC, Gest SD, Ahn H-J. Popularity as an organizing factor of preadolescent friendship networks: Beyond prosocial and aggressive behavior. J Res Adolesc. 2013;23:413-23. doi:10.1111/jora.12033.

Molano A, Jones SM, Brown JL, Aber JL. Selection and socialization of aggressive and prosocial behavior: The moderating role of social-cognitive processes. J Res Adolesc. 2013;23:424-36. doi:10.1111/jora.12034.

Ojanen T, Grönroos M, Salmivalli C. An interpersonal circumplex model of children's social goals: Links with peer-reported behavior and sociometric status. Dev Psychol. 2005;41:699-710. doi:10.1037/0012-1649.41.5.699.

Olthof T, Goosens F. Bullying and the need to belong: Early adolescents' bullyingrelated behavior and the acceptance they desire and receive from particular classmates. Soc Dev. 2007;17:24-46. doi:10.1111/j.1467-9507.2007.00413.x.

Potocnjak M, Berger C, Tomicic T. Una aproximación relacional a la violencia escolar entre pares en adolescentes chilenos: Perspectiva adolescente de factores intervinientes. Psykhe. 2011;20:39-52. doi:10.4067/S0718-22282011000200004.

Prinstein M, Cillessen AHN. Forms and functions of adolescent peer aggression associated with high levels of peer status. Merrill-Palmer Q. 2003;49:310-42.

Raudenbush S, Bryk A. Hierarchical linear models: Applications and data analysis methods. Newbury Park: Sage; 2002.

Rodkin PC, Berger C. Who bullies whom? Social status asymmetries by victim gender. Int J Behav Dev. 2008;32:473-85. doi:10.1177/0165025408093667.

Rodkin PC, Farmer TW, Pearl R, Acker RV. They're cool: Social status and peer group supports for aggressive boys and girls. Soc Dev. 2006;15:175-204. doi:10.1046/j.1467-9507.2006.00336.x.

Rose A, Swenson L, Waller E. Overt and relational aggression and perceived popularity: Developmental differences in concurrent and prospective relations. Dev Psychol. 2004:40:378-87. doi:10.1037/0012-1649.40.3.378.

Salmivalli C. Bullying and the peer group: A review. Aggress Violent Behav. 2010;15:112-20. doi:10.1016/j.avb.2009.08.007.

Salmivalli C, Voeten M. Connections between attitudes, group norms, and behaviors associated with bullying in schools. Int J Behav Dev. 2004;28:246-58. doi:10.1080/01650250344000488

Shi B, Xie H. Popular and nonpopular subtypes of physically aggressive preadolescents: Continuity of aggression and peer mechanisms during the transition to middle school. Merrill-Palmer Q. 2012;58:530-53. doi:10.1353/mpq.2012.0025.

Sijtsema J, Veenstra R, Lindenberg S, Salmivalli C. Empirical test of bullies' status goal: Assessing direct goals, aggression, and prestige. Aggress Behav. 2009:35:57-67. doi:10.1002/ab.20282.

Van Goethem A, Scholte R, Wiers R. Explicit- and implicit bullying attitudes in relation to bullying behavior. J Abnorm Child Psychol. 2010;38:829-42. doi:10.1007/s10802-010-9405-2.

Veenstra R, Dijkstra JK. Transformations in adolescent peer networks. In: Relationship pathways: From adolescence to young adulthood. 2011. p. 135-54.

Wei HS, Chen JK. The moderating effect of machiavellianism on the relationships between bullying, peer acceptance, and school adjustment in adolescents. Sch Psychol Int. 2012;33:345-63. doi:10.1177/0143034311420640.

Zimmer-Gembeck M, Nesdale D, McGregor L, Mastro S, Goodwin B, Downey G. Comparing reports of peer rejection: Associations with rejection sensitivity, victimization, aggression, and friendship. J Adolesc. 2013;36:1237-46. doi:10.1016/j.adolescence.2013.10.00

\section{Submit your manuscript to a SpringerOpen ${ }^{\circ}$ journal and benefit from:}

- Convenient online submission

Rigorous peer review

- Immediate publication on acceptance

- Open access: articles freely available online

- High visibility within the field

- Retaining the copyright to your article

Submit your next manuscript at $\boldsymbol{s p r i n g e r o p e n . c o m ~}$ 